\title{
SEXUAL FUNCTION IN THE NORMAL AND IN PARAPLEGIA
}

\author{
By Edward Tarabulcy, M.D., F.A.C.S. \\ Department of Urology, The Geisinger Medical Centre, \\ Danville, Pennsylvania, U.S.A.
}

\section{NORMAL PHYSIOLOGY}

THE SEXUAL ACT IN THE MALE

THE physical aspect of the sexual act consists of three phenomena: erection, ejaculation and orgasm.

Erection. Erection is achieved by tumescence of the penile corpora through hyperaemia-due to vasodilatation and to opening of the arterio-venous shunts. This is mediated by the parasympathetic nervous system and, to a lesser extent, the sympathetic nervous system. Erection is sustained by compression of the veins between the expanded corpora and the tunica albuginea.

Ejaculation. Ejaculation consists of two parts: seminal emission and ejaculation proper.

A. Seminal emission. This is caused by peristalsis of the smooth muscles of the vasa deferentia, seminal vesicles and prostate. This phase is dependent upon the sympathetic nervous system.

B. Ejaculation proper. This is brought about by clonic contractions mainly of the bulbo-spongiosus and ischio-cavernosus muscles and also of the muscles of the pelvic floor. These are skeletal muscles therefore, the somatic nervous system is responsible for this phase.

Thus, in the sexual act, which is so dependent on the nervous system, all three -namely, the parasympathetic, sympathetic and somatic-components of the peripheral nervous system come into play.

Orgasm. Orgasm is a sensation caused by contraction of the smooth muscles of the internal sexual organs and the striated muscles of the perineum and pelvic floor, coinciding with seminal emission and ejaculation proper.

\section{THE SEXUAL ACT IN THE FEMALE}

In the female there is a corresponding sequence of events. The equivalent of erection is tumescence of the clitoris and labia minora; the equivalent of seminal emission is contraction of the smooth muscles of the uterine tubes and uterus: the equivalent of ejaculation proper is the rhythmic contraction of the bulbo-spongiosus (sphincter vaginae) and ischio-cavernosus muscles and of the pelvic floor and orgasm accompanies emission and ejaculation.

\section{INNERVATION}

THE SPINAL REFLEX ARC

Peripheral Afferent Stimuli (figs. I, 2). The stimuli of light touch to the external genitals and friction to the pendile skin are transmitted along the pudendal 


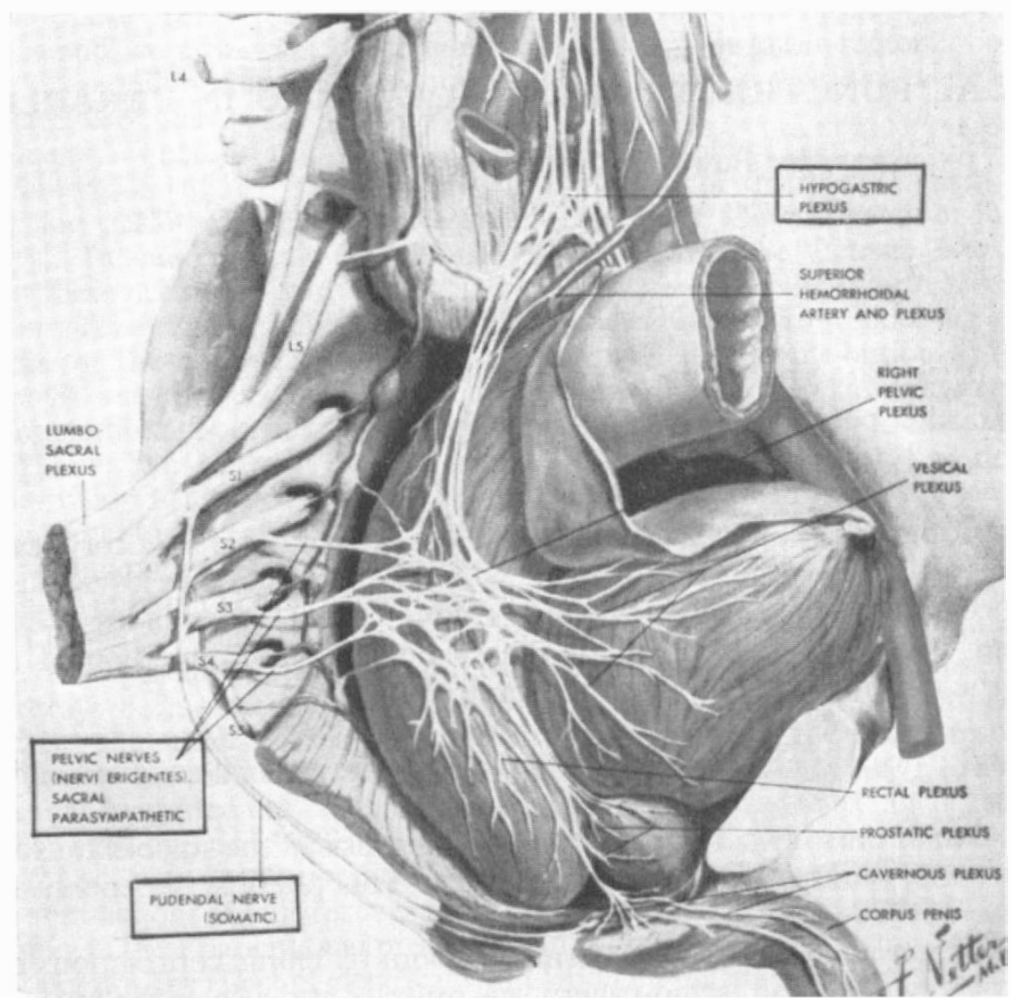

FIG. I

Copyright I953 and 1962, CIBA Pharmaceutical Company, Division of $C I B A$-Geigy Corporation. Reproduced with permission from the CIBA COLLECTION OF MEDICAL ILLUSTRATIONS by F. H. Netter, M.D. All rights reserved.
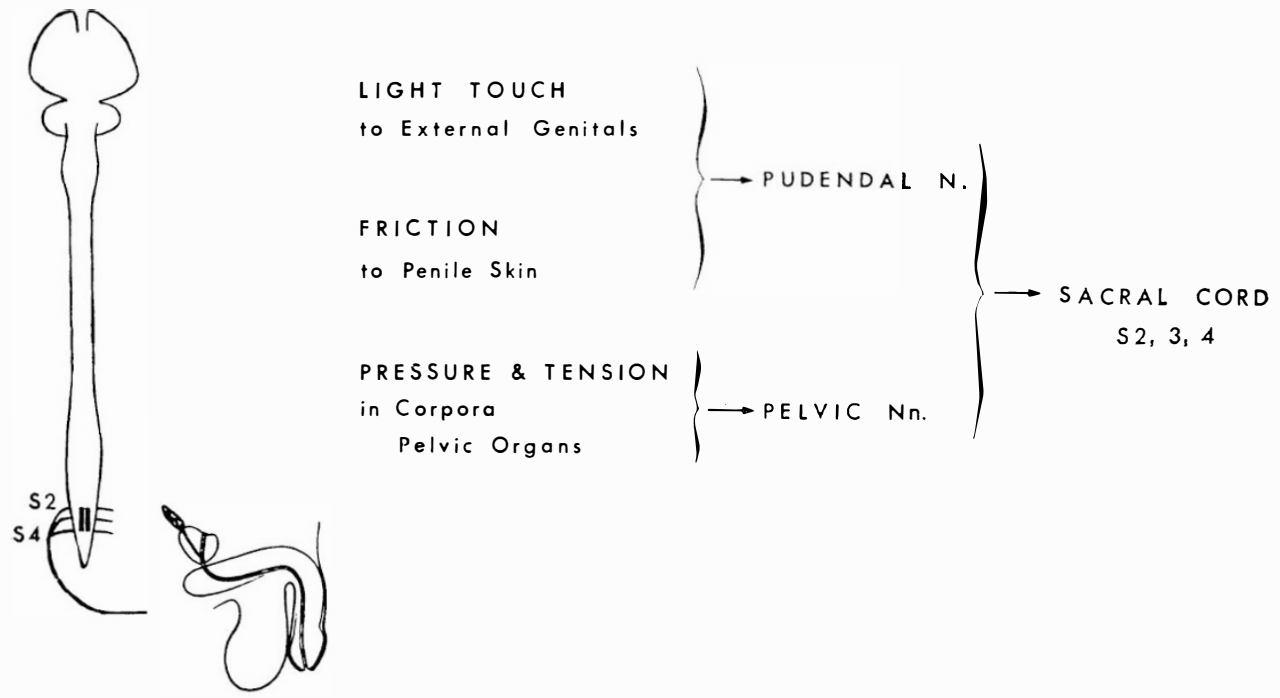

FIG. 2

Peripheral afferent stimuli. 
nerve. The proprioceptive stimuli of pressure and tension in the penile corpora and pelvic organs are transmitted along the pelvic splanchnic nerves. (Erections resulting from such enteroceptive stimuli have been termed 'spontaneous', because the stimuli are not apparent.) Both the pudendal and pelvic nerves end in the second, third and fourth sacral cord segments.

Spinal Cord Centres (fig. 3). There are two centres for erection: a parasympathetic centre located in the second, third and fourth sacral cord segments, known as 'the peripherally or reflexly-activated centre', and a sympathetic centreextending from cord segments TII to L2-known as 'the centrally and psychogenically-activated centre'.

There is one centre for seminal emission, namely, the sympathetic centre, extending from TII to L2. There is one centre for ejaculation proper, a somatic centre, lying in cord segments S2, 3 and 4 .

Peripheral Efferents (fig. 4). From the parasympathetic centre in cord segments $\mathrm{S}_{2}, 3$ and 4, nerve fibres run in the pelvic splanchnic nerves, which are also known as the nervi erigentes. They supply the corpora cavernosa, giving rise to erection, and the prostatic glands, leading to the formation of seminal fluid.

The sympathetic centre lies in cord segments $\mathrm{TII}_{\mathrm{I}}$ to $\mathrm{L}_{2}$. Its fibres travel along the hypogastric nerve and go to the vasa deferentia, seminal vesicles and prostatic muscle fibres, giving rise to seminal emission. Some cholinergic sympathetic fibres in the hypogastric nerve supply the corpora cavernosa and give rise to erection.

From the somatic centre in the second, third and fourth sacral cord segments, nerve fibres run in the pudendal nerve and supply the bulbo-spongiosus and ischiocavernosus muscles and the muscles of the pelvic floor giving rise to ejaculation proper.

\section{SUPRANUCLEAR PATHWAYS}

Afferent Spinal Tracts. Sensations of light touch and friction are transmitted along all three spinal columns. Proprioceptive impulses are transmitted along the posterior column. Eventually, they all reach the cerebral cortex.

Central Afferent Stimuli. Olfactory, visual, auditory and somaesthetic stimuli-by direct perception and by recall-reach the cerebral cortex then the sympathetic and parasympathetic nuclei of the hypothalamus.

\section{Efferent Spinal Tracts.}

I. Somatic Efferents. From the cerebral cortex, the pyramidal tract extends to the spinal anterior horn cells.

2. Visceral Efferents. From the hypothalamus:

(a) to the sympathetic preganglionic cells in the thoraco-lumbar lateral horn;

(b) to the sacral parasympathetic preganglionic cells;

(c) The parependymal fasciculus travels to the lumbo-sacral cord.

When it is divided, testicular atrophy is said to occur.

\section{CLINICAL RESULTS OF SPINAL CORD DAMAGE}

These are influenced by three main factors. 


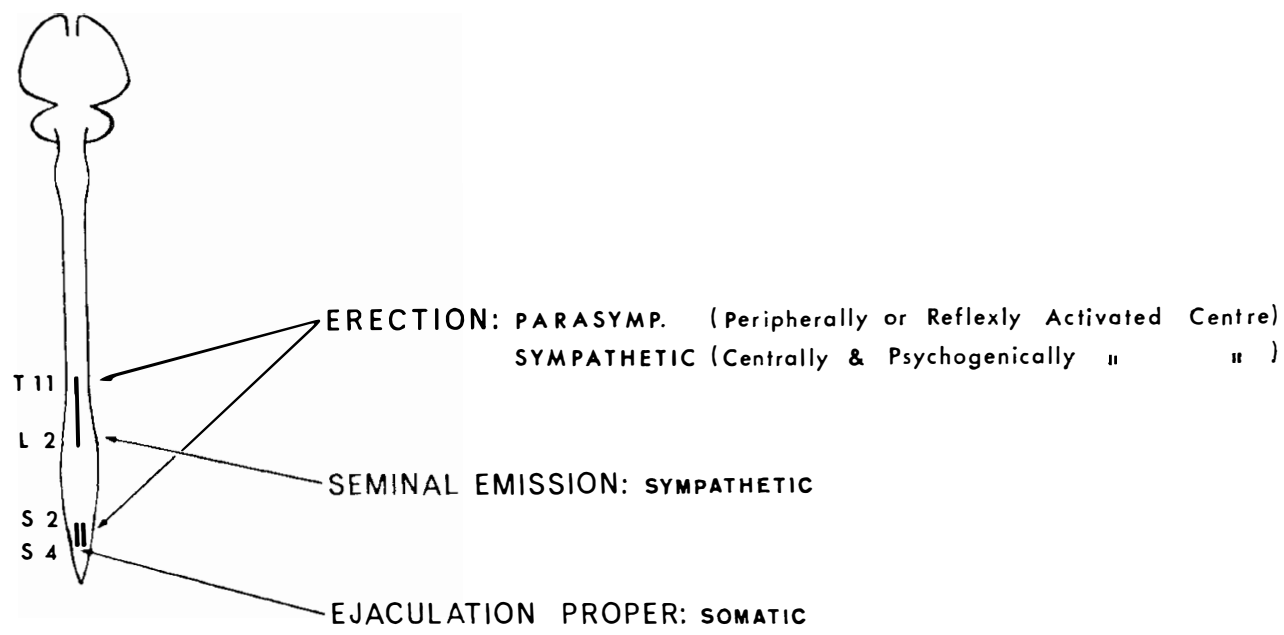

FIG. 3

Spinal cord centres.
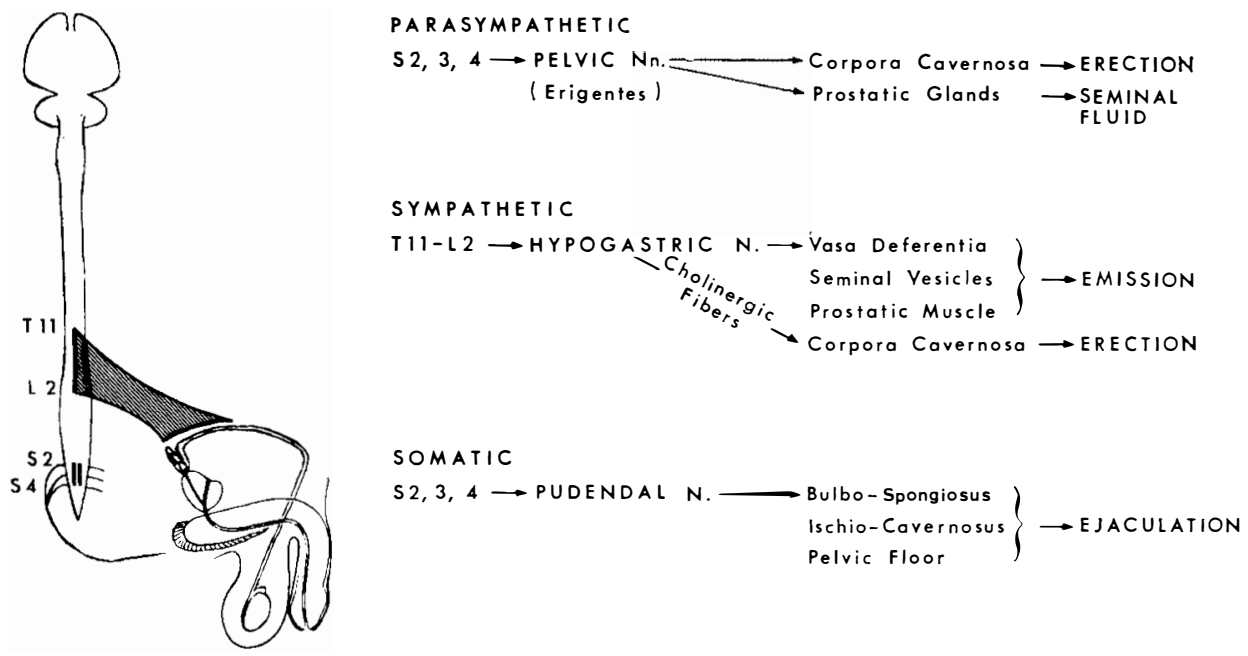

FIG. 4

Peripheral efferents.

I. The Different Vulnerability of the Various Functions. Sexual functions are more vulnerable than micturition which, in turn, is more vulnerable than defaecation. Of the sexual functions themselves, orgasm and ejaculation are more vulnerable than erection and are, therefore, lost more frequently. This is strikingly demonstrated in Table I.

This table shows sexual function in six series comprising 1296 patients (Munro et al., 1948; Kuhn, I950; Talbot, 1955; Zeitlin et al., 1957; Bors \& Comarr, 
I960 and Comarr, I970). We find that Erection js preserved seven to eight times as often as ejaculation and also, that successful coitus was reported in less than half the patients who had erection. The reasons for this are psychological and social factors, muscular disability and, in some cases, short-lived erections.

\section{TABLE I}

Sexual Function in 6 Series of I296 Patients

$\begin{array}{lc} & \% \\ \text { Erection } & 77 \\ \text { Coitus } & 35 \\ \text { Ejaculation } & \text { IO } \\ \text { Progeny } & 3.4\end{array}$

II. The Level of the Cord Lesion. Erection is more frequent with higher lesions: a longer caudal stump means more synapses and, therefore, presumably greater facilitation.

As for ejaculation, its incidence increases with a descending level of the lesion. Thus, patients with a lower motor neurone lesion are more liable to have ejaculation than those with an upper motor neurone lesion. Here, the intact sacral cord appears to have an inhibitory effect. These points are illustrated in Figures 5 and 6 .

Figure 5 (Bors, 1948; Munro et al., 1948; Bors et al., 1950; Kuhn, I950; Talbot, 1955; Zeitlin et al., 1957) shows the relationship between the level of the spinal cord lesion and erection. Erection was preserved in 93 per cent of cervical lesions, 74 per cent of thoracic, 63 per cent of lumbar and 56 per cent of sacral lesions.

Shown in Figure 6 (Munro et al., I948; Kuhn, 1950; Zeitlin et al., 1957) is the relationship between the level of the spinal cord lesion and ejaculation. Sacral cord lesion patients had ejaculation in I 4.3 per cent. of cases; lumbar cord lesion patients in I4 per cent.; thoracic cord lesion patients in 6 per cent.; and cervical cord lesion patients in 3 per cent. of cases.

It should be pointed out, however, that in patients with sacral lesions, because of striated muscle paralysis, ejaculation is not projectile, but dribbling in nature.

Whelan (1972) applied an electrical massager (fig. 7) to the surface of the penis in 63 paraplegic and tetraplegic patients who could not have ejaculation. He was able to induce ejaculation in 12 of the 63 (seven tetraplegics and five paraplegics). Thus, in this group the overall incidence of ejaculation went up from Io per cent. to 27 per cent.

Guttmann and Walsh (197I) have made the outlook far brighter. By injecting $0.3 \mathrm{mg}$. of prostigmin intrathecally, they produced ejaculation in 78 out of 134 paraplegics and tetraplegics. Thus, the incidence of ejaculation in this group rose from Io per cent. to 62 per cent.

III. The Extent or Completeness of the Cord Lesion. Sexual function is much better with a partial cord lesion than with complete trans-section.

Thus, Bors and Comarr (1960) (Table II) found erection in only 26 per cent. of patients with complete lesions of the lower motor neurone, but in 90 per cent. 


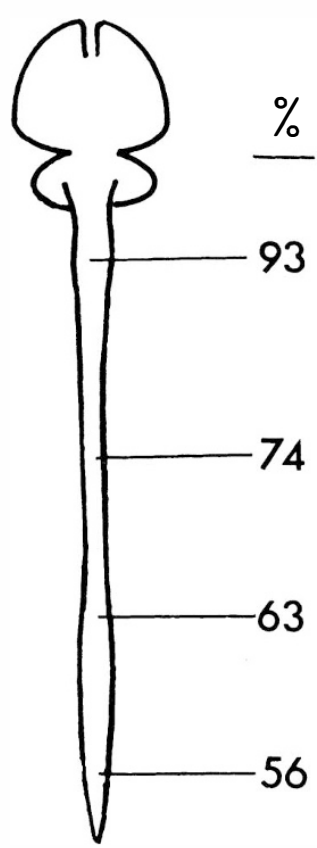

FIG. 5

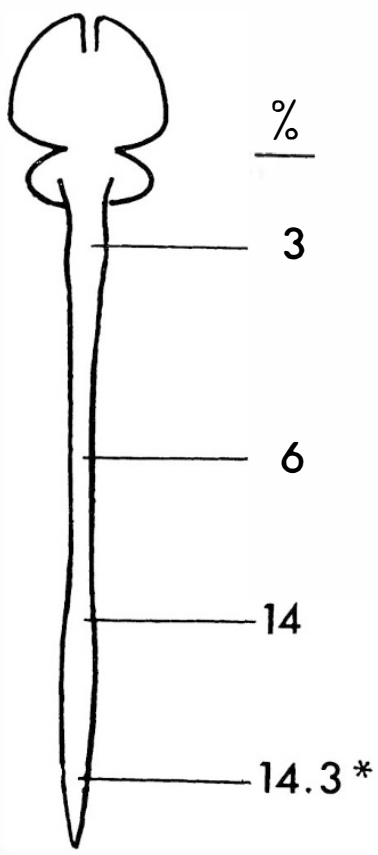

* Dribbling

Fig. 5.-The level of spinal cord lesion and erection in six series of 808 patients.

Fig. 6.-The level of spinal cord lesion and ejaculation in three series of 209 patients.

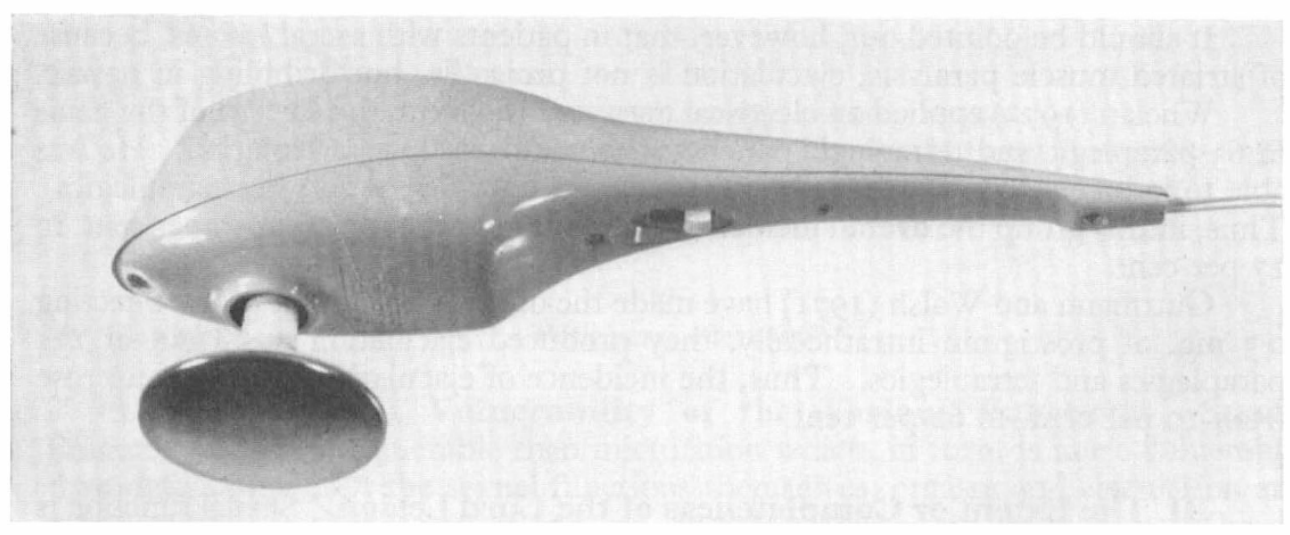

FIG. 7

The electrical massager applied to the penis of paraplegic patients who could not have ejaculation. 
of those with incomplete lesions. Ejaculation occurred in only 18 per cent. of cases with complete lower motor neurone lesions, but in 70 per cent. of those with incomplete lesions. Again, whereas ejaculation was found in 5 per cent. of complete upper motor neurone lesion patients, this figure goes up to 32 per cent. in patients with incomplete lesions.

TABLE II

Sexual Function with Various Types of Spinal Cord Lesions

\begin{tabular}{|c|c|c|c|}
\hline $\begin{array}{c}\text { Bors and Comarr } \\
\text { (529 cases) }\end{array}$ & Erection & Ejaculation & Progeny \\
\hline & $\%$ & $\%$ & $\%$ \\
U.M.N.L. Complete & 93 & 5 & I \\
Incomplete & 99 & 32 & 6 \\
L.M.N.L. Complete & 26 & 18 & 5 \\
Incomplete & 90 & 70 & I0 \\
\hline
\end{tabular}

\section{PROGENY}

In the female, fertility is unimpaired and delivery can be either normal or by Caesarian section.

Among males, only I to 5 per cent. have sired children. This is due to:

(a) The fact that only about 35 per cent. of paraplegics have had successful coitus.

(b) Loss of ejaculation in the majority of paraplegics. This latter factor has now been altered since more paraplegics can have ejaculation by using the electrical massager, and many more by intrathecal prostigmin injection.

(c) Impaired spermatogenesis-the cause of which may be neurogenic (vide supra), nutritional, hormonal or infective (secondary to urinary tract infection).

(d) Scarring and blockage of the seminal passages as a result of infection.

\section{CONCLUSION}

I. Paraplegia may be associated with disturbances of sexual function.

2. Patients with a partial cord lesion fare much better than those with a complete lesion.

3. Patients with 'high' cord lesions are more liable to retain erection than those with 'low' lesions, and the reverse is true of ejaculation.

4. Erection is preserved in 77 per cent. of paraplegics. We have two cord centres for erection: a reflexly activated sacral centre and a centrally and psychogenically activated thoraco-lumbar centre. Therefore, in a patient with a supranuclear (supra-sacral) lesion, we should concentrate mainly on reflex stimulation of erection, while with a nuclear (sacral) lesion we should pay more attention to cranial-nerve stimulation.

5. Ejaculation is preserved in ro per cent. of paraplegics. This figure may be increased to approximately 27 per cent. by using an electrical massager, and to approximately 62 per cent. by intrathecal prostigmin injection. 
6. As for progeny, the two above procedures have markedly improved the outlook for male paraplegics.

In female paraplegics, fertility and child-bearing are unimpaired.

\section{REFERENCES}

Bors, E. (I948). Veterans Administration Technical Bull. TB I0-503, 26.

Bors, E., Engle, E. T., Rosenquist, R. C. \& Holliger, V. H. (I950). F. Clin. Endocrinol. I0, 38I.

Bors, E. \& Comarr, A. E. (1960). Urol. Surv. ז0, I9I.

COMARR, A. E. (1970). Urol. Int. 25, I34.

Guttmann, L. \& Walsh, J. J. (I97I). Paraplegia, 9, 39.

KuHN, R. A. (1950). Brain, 73, I.

Munro, D., Horne, H. W., Jr. \& Paull, D. P. (1948). New Eng. F. Med. 239, 903.

TALBOT, H. S. (1955). F. Urol. 73, 91.

Whelan, J. (I972). Personal Communication.

Zeitlin, A. B., Cottrell, T. L. \& LlOYd, F. A. (1957). Fertility and Sterility, 8, 337. 